\title{
Table of Ming Reign Periods
}

\begin{tabular}{lll}
\hline Reign title & Reign years & Personal name \\
\hline Hongwu & $1368-1398$ & Zhu Yuanzhang. Temple name: Taizu \\
Jianwen & $1399-1402$ & Zhu Yunwen \\
Yongle & $1403-1424$ & Zhu Di \\
Hongxi & 1425 & Zhu Gaozhi \\
Xuande & $1426-1435$ & Zhu Zhanji \\
Zhengtong & $1436-1449$ & Zhu Qizhen \\
Jingtai & $1450-1456$ & Zhu Qiyu \\
Tianshun & $1457-1464$ & Zhu Qizhen (restored) \\
Chenghua & $1465-1487$ & Zhu Jianshen \\
Hongzhi & $1488-1505$ & Zhu Youtang \\
Zhengde & $1506-1521$ & Zhu Houzhao \\
Jiajing & $1522-1566$ & Zhu Houzong \\
Longqing & $1567-1572$ & Zhu Zaihou \\
Wanli & $1573-1619$ & Zhu Yijun \\
Taichang & 1620 & Zhu Changluo \\
Tianqi & $1621-1627$ & Zhu Youjiao \\
Chongzhen & $1628-1644$ & Zhu Youjian \\
\hline
\end{tabular}



Amid cloudy mountains, layers of green embrace a pure stream; The sky is a bright mirror over ten thousand acres of autumn.

The thousand miles of Huguang's Xiang River have long been here;

[In studying] a hundred years of literary offerings we also start at the beginning.

In all the world, where is there not true happiness?

The dynasty today [takes schools] as part of the grand strategy.

The [standards of the] White Deer Grotto and Songyang [Academies] are

within reach;

Gladly I cry that our Way carries on these excellent traditions.

All over $\mathrm{Chu}$, the green plane trees, with a vein going through;

The blue mountains and green water have the same appeal.

Long ago the Censor Donghu (Wu Tingju) inscribed his thoughts;

The community school existing today has the old national style.

The happiness is not forgotten: the various scenes remain.

My lofty feelings I always entrust to poetry.

Alone and pitifully old, in this place where I have been before,

I grasp my brush to inscribe a poem. My thoughts are very full.

—attributed to Liu Daxia 
